\title{
Modulation of Tight Junction Structure and Function by Kinases and Phosphatases Targeting Occludin
}

\author{
Max Johannes Dörfel and Otmar Huber \\ Institut für Biochemie II, Universitätsklinikum Jena, Friedrich-Schiller-Universität Jena, Nonnenplan 2, 07743 Jena, Germany \\ Correspondence should be addressed to Otmar Huber, otmar.huber@med.uni-jena.de
}

Received 15 July 2011; Accepted 22 August 2011

Academic Editor: Sanford I. Bernstein

Copyright ( $) 2012$ M. J. Dörfel and O. Huber. This is an open access article distributed under the Creative Commons Attribution License, which permits unrestricted use, distribution, and reproduction in any medium, provided the original work is properly cited.

Tight junctions (TJs) typically represent the most apical contacts in epithelial and endothelial cell layers where they play an essential role in the separation of extracellular or luminal spaces from underlying tissues in the body. Depending on the protein composition, TJs define the barrier characteristics and in addition maintain cell polarity. Two major families of integral membrane proteins form the typical TJ strand network, the tight junction-associated MARVEL protein (TAMP) family members occludin, tricellulin, and MarvelD3 as well as a specific set of claudins. Occludin was the first identified member of these tetraspanins and is now widely accepted as a regulator of TJ assembly and function. Therefore, occludin itself has to be tightly regulated. Phosphorylation of occludin appears to be of central importance in this context. Here we want to summarize current knowledge on the kinases and phosphatases directly modifying occludin, and their role in the regulation of TJ structure, function, and dynamics.

\section{Introduction}

Tight junctions (TJs) represent the uppermost cell-cell-contact sites at the lateral membrane interface of endothelial or epithelial cells. In freeze-fracture electron microscopy, TJs appear as a set of branched anastomosing strands of protein particles which bring opposing cell membranes into close contacts [1]. It is still a matter of debate whether and how plasma membranes are involved in contact formation at these "kissing points" separating the extracellular space and the inner milieu. As belt-like strands around the cells, TJs seal the paracellular clefts between neighboring cells and thus provide a barrier which protects the organism against passage of toxins or microorganisms and regulates the paracellular passage of ions, water, and other solutes [2]. The specific protein composition of tight junctional complexes defines the barrier characteristics and generates leaky or tight cell layers. The permeability of epithelial cell layers can be evaluated at two different levels. The transepithelial electrical resistance (TER) representing the contribution of both the paracellular resistance ( $R$ para, reflecting the resistance of the TJs) and the transcellular resistance $(R$ trans, reflecting the resistance of the apical and basolateral membranes) can be measured by two-path impedance spectroscopy to determine the permeation of ions [3]. At the second level, the flux of tracers of different sizes evaluates the TJ pore size. In addition, TJs act as a fence that maintains cell polarity, by blocking the free diffusion of proteins and lipids between the apical and basolateral domains of the plasma membrane [4].

In association with a set of intracellular scaffolding proteins including the PDZ-domain-containing zonula occludens proteins ( $\mathrm{ZO}-1, \mathrm{ZO}-2$, and $\mathrm{ZO}-3$ ), the MAGI proteins (MAGI1, MAGI2, and MAGI3), PAR-3 and -6, MUPP, and PATJ (reviewed in [5]), TJs are connected with the cytoskeleton and form a regulatory platform mediating responses to intracellular and extracellular signals. The domain composition of the ZO-proteins containing three N-terminal PDZ domains, which are followed by a Src-homology 3 (SH3) and a guanylate kinase (GUK) domain classifies them as members of the membrane-associated guanylate kinase homologues (MAGUK) protein family. ZO-1 and ZO-2 in addition are characterized by a C-terminal extension including an acidic module and a proline-rich region, which is involved in the association of TJs with the actin cytoskeleton. Despite their similar domain structure, the ZO-proteins have distinct activities and only partially compensate each other's function 
$[6,7]$. Especially, ZO-3 requires preassociation of ZO-1 and/ or ZO-2 and cannot bind to junctional areas by itself [8]. The modular composition of these PDZ domain-containing proteins allows them to mediate multiple interactions with other factors to assemble cytoskeletal and signaling molecules around the integral tight junctional proteins. Other proteins such as cingulin and symplekin have been shown to associate with the cytoplasmic tight junctional plaque acting either as scaffolding or modulatory proteins (for review see [9]).

The identification of occludin as the first tetraspanin protein of the TJ nearly twenty years ago by Furuse et al. [10] started a new area in tight-junction research. Now in addition to occludin, at least 24 claudins are known which specify the barrier properties of epithelia in different organs and tissues. Like occludin, claudins are integrated into the membrane by four transmembrane domains; however, they only have short cytosolic $\mathrm{N}$ - and C-terminal sequences resulting in an apparent molecular mass of about $23 \mathrm{kDa}$. Despite their common tetraspanin structure and colocalization, occludin and claudins show no sequence similarity and thus apparently represent separate phylogenetically unrelated protein families. The tissue-specific expression pattern of the claudins meanwhile has been analyzed in much detail, and many claudins have been studied with respect to their functional properties as sealing or pore-forming proteins. Knockout of distinct claudins provided further insight into the physiological role of the different claudins. More details on structural and functional aspects of claudins are provided by recent comprehensive reviews [11-14].

Meanwhile, tricellulin (MarvelD2) and MarvelD3 have been characterized as further TJ-specific tetraspanin proteins which together with occludin form the TJ-associated marvel proteins (TAMPs), which share a conserved MARVEL (MAL and related proteins for vesicle trafficking and membrane link) domain of four transmembrane domains linked by two extracellular (ECL) and one intracellular loop (ICL) [15]. As indicated by its name, tricellulin preferentially is located at tricellular TJs where it forms a barrier to macromolecules [16]. In addition, tricellulin has an essential role in TJ formation. Knockdown of tricellulin affects tricellular TJs but in addition also results in disorganized bicellular TJ strand continuity [17]. MarvelD3, a recently discovered third member of the TAMPs, is preferentially localized in bicellular TJs and is not essential for TJ formation $[18,19]$. Obviously, the three TAMPs have overlapping functions that cannot be completely compensated by the other members [18]. Discrepant results have been reported in the literature whether TAMP proteins may form heteromeric complexes [18, 20].

In addition to the tetraspanin proteins, different members of the immunoglobulin superfamily of adhesion receptors have been localized to TJs including the junctional adhesion molecules (JAMs) (reviewed in $[21,22]$ ), coxsackie adenovirus receptor (CAR) [23] and ESAM [24]. These single transmembrane domain proteins are assumed to be involved in early steps of contact formation during TJ assembly and in TJ modulation. They are not able to reconstitute TJ strands by themselves and are assumed to be associated laterally to the TJs (for review see [4]).

\section{Occludin in Tight Junctions}

Human occludin is encoded on chromosome $5 q 13.1$ as a protein of 522 amino acids [25]. At least, four splice variants have been identified at the mRNA level which appear to exhibit altered subcellular distribution and are in part generated by alternative promoter usage [26]. Occludin is expressed in epithelial cells but is not detectable in fibroblasts. Antibodies against occludin detect a set of bands around $60 \mathrm{kDa}$, which either are products of alternative splicing or represent proteins carrying posttranslational modifications. Most studies on occludin were performed with the 522 amino acid protein. Thus, in the following when we use the term occludin, we refer to the 522 amino acid protein or its homolog in other organisms.

After the initial identification of occludin numerous studies were performed to analyze its expression and function in more detail. Overexpression of occludin in insect Sf9 cells resulted in the formation of intracellular multilamellar bodies suggesting that occludin is in principle able to form tight junction strands [27]. However, when occludin was expressed in epithelial MDCK cells, it was integrated into TJs and induced an increase in TER but unexpectedly also increased paracellular flux [28, 29]. Treatment of cells with peptides from the extracellular loops of occludin impaired membrane localization and barrier function of occludin although discrepant results were observed for ECL1- and ECL2-derived peptides (for review see [30]). Further studies revealed that in addition to the ECLs at least one occludin transmembrane domain is involved in the regulation of paracellular permeability [31].

Unexpectedly, occludin knock-out mice were viable and showed normal TJ strand formation suggesting that occludin is not essential for barrier formation. However, the animals displayed other signs of pathological disorders such as growth retardation, testicular atrophy and male infertility, dysfunction of the salivary gland, calcification in the brain, thinning of the compact bone, and gastric inflammation and mucus cell hyperplasia $[32,33]$. This finally led to the identification of the first claudins 1 and 2 [34] as major constituents of TJs which are able to reconstitute TJ strands and to recruit occludin to the TJs [35]. In occludin knockdown MDCK cells, TJs were formed and revealed an apparently normal morphology. Interestingly, the expression of distinct claudins was changed, and the ability to extrude apoptotic cells from the monolayer was reduced [36]. Moreover, knockdown of occludin results in an enhanced localization of tricellulin into bicellular TJs suggesting that occludin is involved in the translocation of tricellulin to tricellular TJs [37]. However, different results were reported probably depending on the cell type used in the studies $[37,38]$. Heteromeric complex formation between occludin and tricellulin may contribute to this mechanism [20]. Recently, the cytoplasmic domain of LSR (lipolysis-stimulated lipoprotein receptor) has been characterized to define tricellular contacts for the recruitment of tricellulin [39].

Together with the observations that TJs can be formed in the absence of occludin, there is compelling evidence that occludin, has a regulatory role in TJs in forming a platform 
for signaling processes. Multiple stimuli have been identified which modulate TJ structure and function including growth factors (such as EGF, TGF $\beta$, HGF, PLGF-1, and VEGF), oxidative stress and thiols, inflammation and cytokines and hormones (for review see [30, 40-43]).

Two recent studies clearly have indicated that cytokineinduced changes in TJ structure and function require occludin in a pathway including myosin light chain kinase (MLCK)-dependent myosin light chain (MLC) phosphorylation triggering perijunctional actomyosin ring condensation and caveolin-1-mediated occludin internalization [38, 44]. Knockdown of occludin attenuated TJ remodeling in MDCK II cells induced by combined treatment with IFN $\gamma$ and TNF $\alpha$ or by latrunculin A treatment, an effect not seen when tricellulin was knocked down [38]. The inhibition of occludin endocytosis by inhibitors or depletion of caveolin-1 in cells or mice prevented TNF $\alpha$-induced barrier changes $[38,44]$. Taken together, this clearly indicates that occludin plays an essential role in the regulation of cytokine-induced barrier properties.

Moreover, the tight junctional plaque attracts numerous signaling molecules involved in RhoA and Racl signaling (for review see [45]) including p114RhoGEF [46] or GEF-H1 [47]. The tight junctional plaque itself includes proteins with NACos (nucleus and adhesion complexes) function, which translocate between junctional complexes and the nucleus where they modulate gene transcription. Both ZO-1 and ZO-2, symplekin, huASH1, and ZONAB represent tight junctional proteins with NACos activities (for review see [48, 49]). Posttranslational modifications, especially phosphorylation/dephosphorylation are critically involved in the regulation of such signaling processes. Based on the assumption that occludin plays a central role in the regulation of TJ assembly and function, phosphorylation of occludin and its consequences have attracted much attention during recent years. Here, we want to focus on kinases and phosphatases, which have been shown to directly target and modify occludin and thus affect its function in TJs. This does not exclude that these kinases or phosphatase do not in addition target other integral or peripheral TJ components.

\section{Tyrosine Phosphorylation of Occludin by Src-Family Kinases (SFKs) and FAK}

The Src family of kinases (SFKs) includes 9 members of nonreceptor tyrosine kinases: c-Src, Lyn, Fyn, Lck, Hck, Fgr, Blk, Yrk, and Yes. c-Src is the most prominent and best studied SFK member and is frequently activated during processes deregulated in cancer such as cell proliferation, migration, survival, and angiogenesis. SFKs are characterized by a highly conserved domain structure composed of four Srchomology $(\mathrm{SH})$ domains and by fatty acid modification of its $\mathrm{N}$-teminus driving translocation to the plasma membrane. $\mathrm{c}$-Src is inactivated by a combined mechanism where the phosphorylation of a C-terminal tyrosine residue close to the tyrosine kinase domain (SH1) induces its interaction with the internal $\mathrm{SH} 2$ phospho-tyrosine-binding domain, and by the interaction of a proline-rich motif in the linker region between $\mathrm{SH} 2$ and $\mathrm{SH} 1$ with the $\mathrm{SH} 3$ domain (for review see [50]).

Early studies suggested that tyrosine kinases of the Src family are critically involved in TJ regulation. Treatment of epithelial MDCK II with hydrogen peroxide disrupts TJs with a subsequent drop in TER, which was reversed by exchange of medium or was inhibited by treatment with catalase and heavy metal chelator TPEN. Tyrosine kinase inhibitors PP2 (4-amino-5-(4-chlorophenyl)-7-(t-butyl)-pyrazolo[3,4-d]pyrimidine) and genistein (49,5,7-trihydroxyisoflavone) blocked reassembly of $\mathrm{TJ}$ after hydrogen peroxide treatment [51]. Similarly, in Ras-transformed MDCK cells with absent occludin-, claudin-1-, and ZO-1-staining at cellcell contacts, treatment with the MEK1 inhibitor PD98059 induced reassembly of tight junctions and increased tyrosine phosphorylation of occludin and ZO-1 [52]. These observations suggested that SFKs are involved in TJ assembly. As a candidate kinase responsible for these effects, c-Yes was identified using a peptide from the coiled-coil domain in the Cterminal domain of occludin [53]. Moreover, depletion of $\mathrm{Ca}^{2+}$ from the cell culture medium induced a rapid dephosphorylation of tyrosine residues in occludin in MDCK II cells. Readdition of $\mathrm{Ca}^{2+}$ reverted this effect, which was inhibited in the presence of the c-Yes inhibitor CGP77675. Indeed, c-Yes colocalizes with occludin at tight junctional cellcell contacts, and an interaction has been recently confirmed at the blood-testis barrier (BTB) as shown by coimmunoprecipitation experiments in sertoli cells isolated from SpragueDawley rats. The inhibition of c-Yes with SU6656 (inhibitor for Src family kinases, with an $\mathrm{IC}_{50}$ of $20 \mathrm{nM}$ for c-Yes but $280 \mathrm{nM}, 170 \mathrm{nM}$ and $130 \mathrm{nM}$ for c-Src, Fyn and Lyn, resp.) results in a redistribution of occludin and N-cadherin from the cell surface to the cytosol and a breakdown in TER [54]. However, direct phosphorylation of occludin by c-Yes was not shown and the residues targeted by c-Yes were not identified. In contrast to the barrier promoting effects of c-Yes, activation and membrane translocation of $\mathrm{c}-\mathrm{Src}$ in response to oxidative stress weakens the barrier properties of Caco2 cells and resulted in redistribution of occludin and ZO-1 from intercellular junctions to the cytosol. Inhibition of c-Src or overexpression of a kinase-dead c-Src K297R protein abrogated these effects. Interestingly, c-Src in contrast to c-Yes delayed relocalization of occludin to TJs after readdition of $\mathrm{Ca}^{2+}$ in $\mathrm{Ca}^{2+}$-switch experiments [55]. The different effects induced by c-Yes and c-Src cannot be explained by the different cell types since c-Src showed a similar mechanism of $\mathrm{TJ}$ regulation in MDCK cells.

In vitro studies confirmed direct binding of c-Src to a GST-occludin C-terminal domain fusion protein and phosphorylation by c-Src-diminished binding of the occludin C-terminus to ZO-proteins from cell lysates but did not affect binding to actin filaments [56]. Tyrosine residues Y398/Y402 in a highly conserved YETDYTT motif in human occludin were identified as the c-Src phosphosites (see Figure 1). Mutation of these residues to alanine abolished c-Src-mediated phosphorylation of occludin in in vitro phosphorylation assays. In $\mathrm{Ca}^{2+}$-switch experiments, a phosphomimetic occludin-Y398D/Y402D construct was impaired in binding to ZO-1 and reassembled into TJs with a 


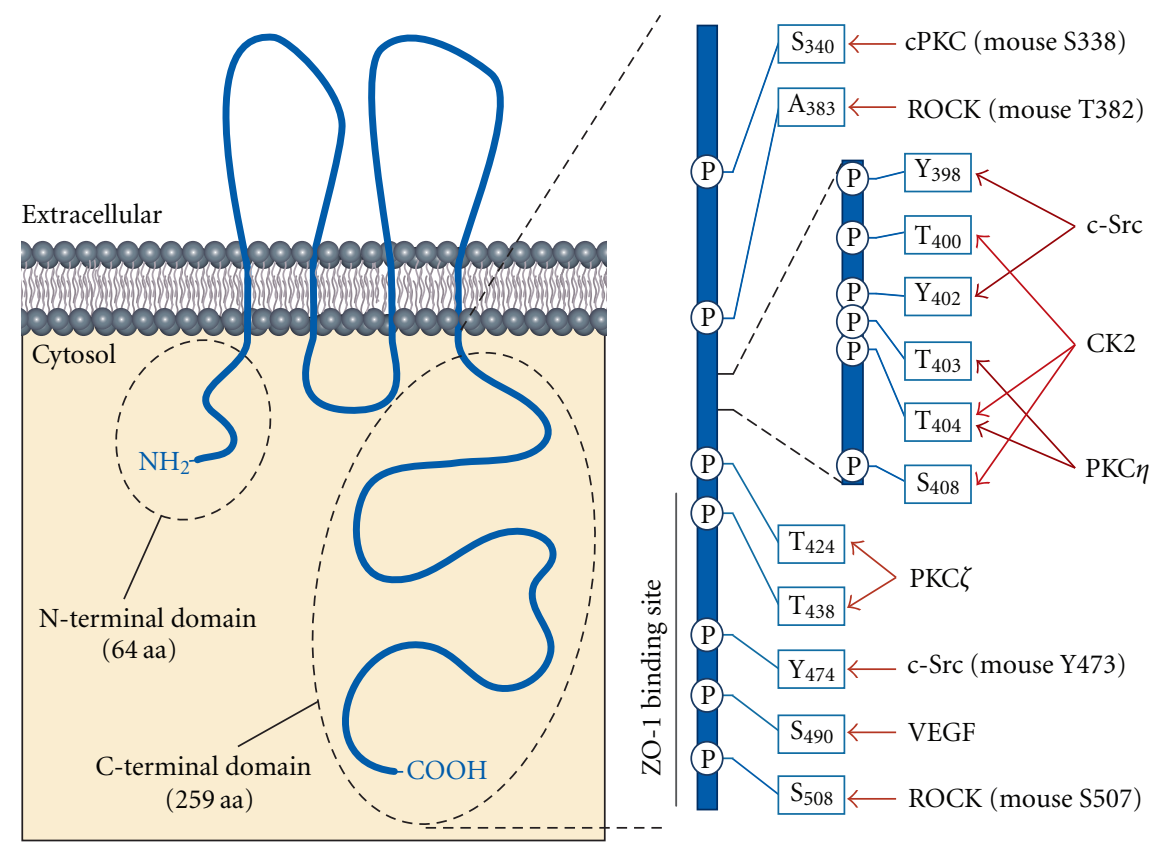

FIgURE 1: Schematic presentation of occludin and localization of the amino acid residues targeted by specific kinases.

significant delay compared to wild-type occludin or occludin Y398A/A402A. In agreement with this, expression of occludin Y398D/Y402D sensitized MDCK cells for hydrogen peroxide-induced barrier disruption [57]. A recent study has identified tyrosine 473 as another putative SFK phosphorylation site using a phosphorylation site-specific antibody. Phosphorylation of Y473 in the occludin C-terminal domain is a prerequisite for its interaction with the $\mathrm{CSH} 2$-domain of the p85 $\alpha$ regulatory subunit of PI3K (also see below). Binding was abolished in cells expressing Y473F-mutated occludin. Phosphorylated occludin thus recruits active PI3K to the leading edges of migrating cells as shown in wound healing assays thereby regulating Racl activation and actin dynamics [58]. A similar translocation of PI3K to junctions and binding to occludin was also observed in response to oxidative stress [59].

Focal adhesion kinase (FAK) represents a highly conserved cytosolic protein tyrosine kinase with essential roles during embryonic development and in the pathogenesis of cancer and cardiovascular disease. Structural analyses revealed an N-terminal FERM (band4.1, ezrin, radixin, and moesin homology), a central catalytic and a C-terminal FAT (focal adhesion targeting) domain composition of FAK. The latter domains are separated by an unstructured proline-rich sequence. FAK plays a central role in the regulation of cell migration, cytoskeleton, and cell adhesion especially by signals from the extracellular matrix in mechanotransduction. Intramolecular binding of the FERM domain to the catalytic domain blocks access to the catalytic cleft and activation of FAK by autophosphorylation of Y397, which in its phosphorylated state, provides a binding site for SKF-members (for review see $[60,61]$ ).

The administration of acetaldehyde to human colonic biopsies activated $\mathrm{c}$-Src and FAK and reduced protein tyrosine phosphatase activity, thereby increasing the tyrosine phosphorylation of occludin, E-cadherin, and $\beta$-catenin concomitant with a redistribution of occludin, ZO-1, E-cadherin, and $\beta$-catenin from the detergent-insoluble to the detergent-soluble fraction and a loss of occludin from intercellular junctions. Pretreatment with EGF or L-glutamine prevented these effects [62]. In sertoli cells, colocalization and interaction of FAK with occludin and ZO-1 was observed. A siRNA-mediated knockdown of FAK resulted in the disruption of barrier function (decrease in TER). In these cells, occludin staining at the plasmamembrane was reduced, as well as its interaction with ZO-1. Moreover, diminished phosphorylation of occludin on tyrosine and serine but not on threonine residues was observed [63]. It is currently not known whether a direct, FAK-mediated phosphorylation of occludin, or a secondary mechanism induced by FAK-dependent modulation of the cytoskeleton is responsible for these effects.

\section{Phosphorylation of Occludin by Rho Kinase (RhoK)}

Rho kinases (RhoK) are serine/threonine kinases that act downstream of the small GTPase Rho with multiple functions in the regulation of the cytoskeleton, polarity and motility of cells [64]. Early studies indicated that Rho signaling is involved in the regulation of TJs. The inhibition of Rho by $\mathrm{C} 3$ transferase-mediated ADP ribosylation resulted in reduced localization of ZO-1 and occludin at cell junctions. $\mathrm{Mu}-$ tant Rho-GTPase expression (dominant-active Rho-V14 or dominant-negative Rho-N19) altered the levels of phosphoserine/phosphothreonine occludin isoforms $[65,66]$. In ECV304 cells, LPA was found to increase the paracellular permeability of the tracer horseradish peroxidase, whereas 
a dominant-negative mutant of RhoA (RhoA T19N) or a specific inhibitor of the downstream RhoK (p160ROCK), Y-27632, prevented these effects. Interestingly, histamine treatment also increases occludin phosphorylation, however, independent of Rho and RhoK [67]. Furthermore, inhibition of Rho was shown to prevent migration of monocytes through the blood brain barrier (BBB). Dominant-negative RhoK and RhoK inhibitors reduced monocyte transmigration and occludin phosphorylation [68]. This suggested, that RhoK directly phosphorylates occludin and other tight junctional proteins. A recent study has identified T382 and S507 in mouse occludin and T207 in claudin-5 as specific target sites of RhoK. The activation of RhoK by LPA induced phosphorylation of these sites and decreases TER in brain microvascular endothelial cells (BMVECs), whereas a RhoK inhibitor (Y27632) prevented the decrease in TER although the phosphorylation of occludin was only partially inhibited [69].

\section{MAP Kinases (MAPKs) and Occludin Phosphorylation}

Mitogen-activated protein kinases (MAP kinases) represent a family of small Ser/Thr kinases (ERK, p38/MAPK, and JNK), which are activated by a cascade of kinases (MAPK kinase, MEK; MAPKK kinase) in response to different growth, stress, and inflammatory stimuli. Deregulated activation is frequently detected in disease including various cancers, inflammatory, and neuronal diseases [70].

Treatment of MDCK cells with the $\mathrm{Na}^{+}, \mathrm{K}^{+}$-ATPase inhibitor ouabain lead to MAPK activation and redistribution of occludin, ZO-1, and other apical junctional complex proteins including E-cadherin from cell-cell contacts and to a concomitant drop in TER [71]. Stable transfection of constitutive active MEK-1 reduced tyrosine phosphorylation of occludin and weakened the barrier, whereas a dominantnegative MEK-1 elevated TER and tyrosine phosphorylation in THCE (SV40-immortalized human corneal epithelial) cells [72]. Similarly, ERK activation with a subsequent breakdown of TJs was observed in epithelial cells expressing constitutively active Ras or Raf- $1[52,73]$. The administration of $\mathrm{H}_{2} \mathrm{O}_{2}$ induces barrier breakdown, as measured by increasing inulin permeability, decreasing TER, redistribution of occludin and ZO-1 from TJs to intracellular compartments, and increasing threonine phosphorylation of occludin in Caco2 cells. However, in this study, the activation of the MAPK by EGF restored the barrier defects, whereas the inhibition of MAPK signaling pathway with the MEK inhibitors (PD98059 and U0126) abolished the protective effect of EGF. Moreover, the authors showed that ERK1 colocalizes with occludin at the TJ and directly interacts with the occludin C-terminal domain in pull-down assays [74]. An explanation for the discrepant results in respect to the role of MAPK is given by a recent study which showed that EGF potentiated $\mathrm{H}_{2} \mathrm{O}_{2}$-induced tight junction disruption in under-differentiated Caco- 2 cell monolayers but prevented $\mathrm{H}_{2} \mathrm{O}_{2}$-induced disruption of tight junctions in differentiated cells. This appears to be due to a differential distribution of ERK in underdifferentiated and differentiated cells. Moreover, EGF differentially modulates the association of PP2A and PKC $\zeta$ with occludin in these cells [75]. In addition to ERK, an interaction of p38/MAPK and PI3K with occludin after treatment with LPS was shown by coimmunoprecipitation experiments [76]. ERK but not p38/MAPK or JNK activation is involved in the EGF-mediated attenuation of TJ disruption in acetaldehyde-treated cells [77]. In contrast, TJ disruption in response to osmotic stress is mediated by JNK2 [78]. The amino acids phosphorylated by MAPK have not been identified so far.

\section{Direct Phosphorylation of Occludin by PKCs}

Protein kinases C (PKCs) represent a family of serine/threonine kinases consisting of nine isoforms that can be classified into three subgroups: the conventional PKCs (cPKCs: $\mathrm{PKC} \alpha, \beta_{\mathrm{I}} / \beta_{\mathrm{II}}$, and $\gamma$ ), the novel PKCs (nPKCs: PKC $\delta, \varepsilon$, $\eta$, and $\theta$ ), and the atypical PKCs (aPKCs: PKC $\zeta$ and $\iota / \lambda$ ). The structural and functional features of these kinases are reviewed in [79].

An early investigation using the pan-PKC inhibitor calphostin $\mathrm{C}$ resulted in a delayed assembly of TJs in $\mathrm{Ca}^{2+}$ switch experiments but did not affect sorting of E-cadherin or of desmoplakin suggesting that PKC is specifically involved in the regulation of TJs. A phosphorylated $65 \mathrm{kDa}$ protein detected in these studies was speculated to represent occludin [80]. Numerous further studies using different PKC inhibitors or activators have provided clear evidence that PKC is involved in the regulation of TJs although data apparently were contradictory. Different cellular systems and conditions, the presence of more than one PKC isoform in a cell, and their specific and probably overlapping functions lead to complex and sometimes difficult to interpret observations also with respect to PKC-dependent occludin phosphorylation. Therefore, it appears to be helpful to identify the specific amino acid residues in occludin, which are phosphorylated by specific PKCs and to mutate them to finally generate occludin variants that no longer can be phosphorylated or that mimic constitutive phosphorylation.

In this respect, in a study using MDCK cells cultivated in low $\mathrm{Ca}^{2+}$-medium to disrupt TJs, treatment of the cells with the PKC activators PMA or diC8 induced redistribution of occludin to cell-cell contacts and to the triton X-100 insoluble fraction. These effects were abolished by the pan-PKC inhibitor GF-109203X. However, the cPKC inhibitor Gö6976 did not inhibit reassembly of occludin into TJs, whereas the nPKC inhibitor rottlerin was active. From these observations, it was concluded that $\mathrm{CPKCs}$ and nPKCs antagonistically regulate assembly of TJs $[81,82]$. In vitro phosphorylation and subsequent mass spectrometric analysis identified Ser338 as a potential cPKC phosphorylation site [81].

In Caco-2 and MDCK cells, occludin interacts with $\mathrm{PKC} \eta$. Overexpression of wild-type PKC $\eta$ or constitutive active $\mathrm{PKC}_{\mathrm{Al} 1 \mathrm{E}}$ increases TER, reduces inulin permeability, and increases occludin staining at the membrane, suggesting augmented barrier properties. These effects could be blocked by shRNA-induced knockdown of PKC $\eta$ or application of PKC $\eta$ pseudosubstrate. Mutational analyses identified three residues (T403, T404, and T438) in the C-terminal 
domain of occludin as target residues of PKC $\eta$ with amino acids T403 and T404 verified by mass spectrometry. Since a single T404A mutation completely abolishes PKC $\eta$-dependent phosphorylation, it was speculated that phosphorylation of T404 may be a prerequisite for the subsequent phosphorylation of T403. Moreover, occludin-T403D/T404D was localized preferentially at the junctional membranes, whereas occludin-T403A/T404A was detected in the intracellular compartment. Interestingly, expression of the occludinT403D/T404D construct enhanced ZO-1 junctional localization, whereas the alanine-mutated occludin had the opposite effect [83].

Atypical PKC $\zeta$ also binds to the occludin C-terminus and phosphorylates it on threonine residues. In addition to amino acids T403 and T404, T424 and T438 were identified as sites phosphorylated by PKC $\zeta$ (summarized in Table 1). Mutation of T424 and T438 to alanine results in a mislocalization of occludin in intracellular compartments and delays its assembly into TJs after $\mathrm{Ca}^{2+}$-induced reassembly of TJs. To specifically address the physiological role of $\mathrm{PKC} \zeta$, kinase activity was inhibited by a pseudosubstrate peptide or by siRNA-mediated knockdown. In MDCK and Caco-2 cells this results in a decreased barrier function as determined by a reduction in TER and an increase in inulin permeability, reduced phosphorylation of occludin, dissociation of occludin from the detergent insoluble fraction, redistribution of occludin to the cytosol and a delay of $\mathrm{Ca}^{2+}$-induced $\mathrm{TJ}$ reassembly [84]. It is not clear whether these effects are specific for phosphorylation of T424 and T434 or in addition depend on phosphorylation of T404 and T403 by PKC $\zeta$. Moreover, aPKC within the polarity complex has been shown to interact with occludin in coimmunoprecipitation experiments [58]. Whether aPKC phosphorylates occludin in this context has to be determined.

\section{Phosphorylation of Occludin by CK1 and CK2}

CK1 and CK2 (formerly known as casein kinase 1 and 2) represent ubiquitously expressed serine/threonine kinases detectable in all eukaryotic organisms. The mammalian CK1 family includes seven isoforms $(\alpha, \beta, \delta, \varepsilon, \gamma 1, \gamma 2$, and $\gamma 3)$ encoded by distinct genes which can be post-transcriptionally processed into a number of splice variants. CK1 is a monomeric kinase which has been shown to be involved in the regulation of diverse cellular processes including Wnt signaling, circadian rhythms, and cytoskeleton maintenance and itself is regulated by posttranslational modifications (for review see [85]). CK1 directly binds and phosphorylates the occludin C-terminus [86]. In addition, in vitro kinase experiments using a GST-occludin N-terminal fusion protein as a substrate revealed phosphorylation of the occludin N-terminus [87]. The amino acids modified by CK1 phosphorylation and the physiological effects are currently unknown.

CK2 is a tetrameric protein with two enzymatic $\alpha$-subunits $\left(\alpha, \alpha^{\prime}\right)$ and two regulatory $\beta$-subunits. Multiple cellular processes including cell proliferation, apoptosis, gene expression, and the circadian rhythm are regulated by CK2. The constitutive active protein appears to be regulated by its subcellular distribution in response to different signals (for review see $[88,89])$. First evidence for a CK2-mediated phosphorylation of occludin was provided by in vitro phosphorylation experiments with the Xenopus laevis occludin C-terminal domain [90]. Later CK2 was purified from porcine brain extracts confirming an interaction of the kinase with occludin [91]. CK2 phosphorylates T375 and S379, and the corresponding amino acids T403 and S407 in Xenopus and mouse occludin, respectively, [90,91]. Mutation of these residues to alanine or aspartate abolishes or at least diminishes phosphorylation of occludin. Our own studies have recently identified $\mathrm{T} 400$ as a third amino acid residue with the cluster T400-X-X-X-T404-X-X-X-S408 in human occludin, which is phosphorylated by CK2. Only mutation of all three residues to alanine resulted in a complete loss of occludin phosphorylation in in vitro phosphorylation assays. Interestingly, introduction of a phospho-mimetic S408E mutation into the occludin C-terminus increased CK2-dependent phosphorylation in comparison to the corresponding triple alanine mutant suggesting that prephosphorylation of S408 enhances phosphorylation of T404 and T400 [87].

Until recently, the physiological consequences of occludin phosphorylation by CK2 were unknown. Studies by Raleigh et al. [92] provided interesting first insight into the sophisticated role of CK2 in the assembly of TJs. Treatment of Caco-2 cells with different CK2 inhibitors or siRNA-mediated knockdown of CK2 resulted in enhanced barrier function as evaluated by increased TER values, reduced paracellular $\mathrm{Na}^{+}$-flux. In line with this, the inhibition of CK2 increased the amount of tight junctional occludin. Interestingly, knockdown of occludin prevented elevation of TER by the inhibition of CK2 activity, suggesting that CK2-dependent regulation of TJ barrier function is occludin-dependent. Expression of EGFP-tagged occludin constructs in Caco-2 cells with knocked down endogenous occludin was used to analyze the mobile fraction of the different occludin constructs in FRAP (fluorescence recovery after photobleaching) experiments. CK2 inhibition reduced the mobile fraction of occludin. Moreover, the mobile fractions of occludin-T404A/ S408A and -S408A were significantly reduced compared to wildtype occludin and occludin-T404D/S408D, -T404A, and -S408D. In addition, Raleigh et al. reported that occludinS408D C-terminal tail binds more endogenous occludin, whereas occludin-S408A associates more efficiently with claudin- 1 and -2 , and this appears to be mediated by ZO-1 acting as a scaffold. However, knockdown of ZO-1 or claudin-2 eliminated TER and $\mathrm{Na}^{+}$-flux responses to CK2 inhibition, indicating an essential role of ZO-1 and claudin-2 in the occludin-mediated response to CK2 inhibition. Finally, the inhibition of CK2 was observed to reverse IL-13-induced, claudin-2-dependent barrier disruption. These data were summarized in a model postulating that phosphorylation of S408 in occludin acts as a switch in the CK2-mediated regulation of $\mathrm{TJ}$ structure and paracellular permeability in determining whether occludin forms mobile homodimers or heterotypic complexes with ZO-1, claudin-1, and claudin2 involved in the control of the TJ paracellular leak pathway [92]. Our own studies using MDCK cells stably transfected with FLAG-tagged wildtype occludin or the 
TABLE 1: Summary of known occludin phosphorylation sites in the context of the kinases or stimuli that induce phosphorylation at these sites and the effects on TJ function generated by induced or inhibited phosphorylation. Green label: kinase overexpression, stimulation or phospho-mimetic occludin variant; red label: kinase knockdown, inhibition or occludin variant that cannot be phosphorylated at the specified amino acid site.

\begin{tabular}{|c|c|c|c|c|}
\hline kinase/site & & ect & Cell type & Reference \\
\hline \multirow{4}{*}{$\begin{array}{c}\mathrm{c}-\mathrm{Src} \\
\mathrm{Y} 398 / \mathrm{Y} 402\end{array}$} & $\begin{array}{l}\text { overexpression/ } \\
\text { stimulation: }\end{array}$ & $\begin{array}{c}\text { TER } \downarrow \\
\text { inulin permeability } \uparrow \\
\text { junctional Occ } \downarrow\end{array}$ & \multirow{4}{*}{$\begin{array}{l}\text { Caco-2 } \\
\text { MDCK } \\
\text { Rat-1 }\end{array}$} & \multirow{4}{*}[55-57]{} \\
\hline & $\begin{array}{l}\text { Y398D/Y402D- } \\
\text { mutation/ } \\
\text { phosphorylation: }\end{array}$ & $\begin{array}{c}\text { TJ-assembly } \downarrow \\
\text { inulin permeability } \uparrow \\
\text { junctional Occ } \downarrow \\
\text { interaction of Occ with ZO-1, } \\
-2 \text { and }-3 \downarrow\end{array}$ & & \\
\hline & $\begin{array}{l}\text { inhibition/ } \\
\text { knockdown: }\end{array}$ & $\begin{array}{c}\text { TER } \uparrow \\
\text { inulin permeability } \downarrow \\
\text { TJ-assembly } \uparrow\end{array}$ & & \\
\hline & $\begin{array}{l}\text { Y398A/Y402A- } \\
\text { mutation: }\end{array}$ & $\begin{array}{c}\text { junctional Occ } \uparrow \\
\text { TJ-assembly } \rightarrow \\
\text { inulin permeability } \rightarrow\end{array}$ & & \\
\hline \multirow{2}{*}{$\begin{array}{c}\mathrm{c}-\mathrm{Src} \\
\text { Y473 (mouse) }\end{array}$} & Y473D-mutation: & $\begin{array}{c}\text { interaction of Occ with } \mathrm{PI} 3 \mathrm{~K} \uparrow \\
\text { increased wound healing } \\
\text { and migration }\end{array}$ & \multirow{2}{*}{$\begin{array}{l}\text { MDCK } \\
\text { A431 }\end{array}$} & \multirow{2}{*}[58]{} \\
\hline & Y473F-mutation: & $\begin{array}{c}\text { interaction of Occ with PI3K } \downarrow \\
\text { attenuated wound healing } \\
\text { and migration }\end{array}$ & & \\
\hline \multirow{2}{*}{$\begin{array}{c}\text { ROCK } \\
\text { (T382)/S507 } \\
\text { (mouse) }\end{array}$} & $\begin{array}{l}\text { overexpression/ } \\
\text { stimulation: }\end{array}$ & TER $\downarrow$ & \multirow{2}{*}{ COS-7 } & \multirow{2}{*}{ [69] } \\
\hline & $\begin{array}{l}\text { inhibition/ } \\
\text { knockdown: }\end{array}$ & TER $\uparrow$ & & \\
\hline $\begin{array}{c}\text { cPKC } \\
\text { S338 (mouse) }\end{array}$ & $\begin{array}{l}\text { overexpression/ } \\
\text { stimulation: }\end{array}$ & $\begin{array}{l}\text { insoluble pool of Occ } \uparrow(?) \\
\text { junctional Occ } \uparrow(?)\end{array}$ & MDCK & {$[81,82]$} \\
\hline \multirow{4}{*}{$\begin{array}{l}\mathrm{nPKC} \eta \\
\mathrm{T} 403 / \mathrm{T} 404 \\
(438)\end{array}$} & $\begin{array}{l}\text { overexpression/ } \\
\text { stimulation }\end{array}$ & $\begin{array}{c}\text { TER } \uparrow \\
\text { inulin permeability } \downarrow \\
\text { junctional Occ } \uparrow\end{array}$ & \multirow{4}{*}{$\begin{array}{l}\text { MDCK } \\
\text { Caco-2 }\end{array}$} & \multirow{4}{*}[82,83]{} \\
\hline & $\begin{array}{l}\text { T403D/T404D- } \\
\text { mutation }\end{array}$ & $\begin{array}{c}\text { TER } \uparrow \\
\text { inulin permeability } \downarrow \\
\text { junctional Occ } \uparrow\end{array}$ & & \\
\hline & $\begin{array}{l}\text { inhibition/ } \\
\text { knockdown: }\end{array}$ & $\begin{array}{c}\text { junctional Occ } \downarrow \\
\text { inulin permeability } \uparrow \\
\text { assembly } \downarrow \\
\text { TER } \downarrow\end{array}$ & & \\
\hline & $\begin{array}{l}\text { T403A/T404A } \\
\text {-mutation }\end{array}$ & $\begin{array}{c}\text { junctional Occ } \downarrow \\
\text { junctional ZO- } 1 \downarrow \\
\text { TER } \downarrow\end{array}$ & & \\
\hline
\end{tabular}


Table 1: Continued.

\begin{tabular}{|c|c|c|c|c|}
\hline kinase/site & & Effect & Cell type & Reference \\
\hline \multirow{2}{*}{$\begin{array}{c}\text { аРКC } \\
\text { T424/T438 } \\
\text { (T403/T404) }\end{array}$} & $\begin{array}{l}\text { inhibition/ } \\
\text { knockdown: }\end{array}$ & $\begin{array}{c}\text { TER } \downarrow \\
\text { permeability } \uparrow \\
\text { Assembly } \downarrow \\
\text { junctional Occ } \downarrow\end{array}$ & \multirow{2}{*}{$\begin{array}{c}\text { Rat-1 } \\
\text { MDCK II } \\
\text { Caco-2 }\end{array}$} & \multirow[t]{2}{*}[84]{} \\
\hline & $\begin{array}{c}\text { T424A- or } \\
\text { T438A-mutation }\end{array}$ & $\begin{array}{c}\text { junctional Occ } \downarrow \\
\text { Assembly } \downarrow\end{array}$ & & \\
\hline \multirow{5}{*}{$\begin{array}{c}\text { CK2 } \\
(\mathrm{T} 400) / \mathrm{T} 404 / \mathrm{S} 408\end{array}$} & S408D-mutation & $\begin{array}{c}\text { junctional Occ } \downarrow \\
\text { Occ exchange } \rightarrow \\
\text { Occ dimerization } \uparrow \\
\text { interaction of occludin with } \\
\text { ZO-1,Cld-1 and Cld- } 2 \downarrow\end{array}$ & \multirow{5}{*}{$\begin{array}{c}\text { Caco-2 } \\
\text { MDCK } \\
\text { T84 }\end{array}$} & \multirow{5}{*}[87,90-92]{} \\
\hline & $\begin{array}{l}\text { inhibition/ } \\
\text { knockdown: }\end{array}$ & $\begin{array}{c}\text { TER } \uparrow \\
\mathrm{Na}^{2+} \text {-flux } \downarrow \\
\text { ZO-1, Cld-1, Cld- } 2 \text { exchange } \uparrow\end{array}$ & & \\
\hline & T404A/S408A & $\begin{array}{c}\text { Occ exchange } \downarrow \\
\text { ZO- } 1 \text {, Cld- } 1 \text {, Cld- } 2 \text { exchange } \uparrow \\
\text { Occ dimerization } \uparrow \\
\text { interaction of occludin with } \\
\text { ZO-1, Cld- } 1 \text { and Cld- } 2 \uparrow\end{array}$ & & \\
\hline & S408A & $\begin{array}{c}\text { junctional Occ } \uparrow \\
\text { Occ exchange } \downarrow \\
\text { ZO-1, Cld-1, Cld-2 exchange } \uparrow \\
\text { Occ dimerization } \downarrow \\
\text { interaction of occludin with } \\
\text { ZO-1, Cld-1 and Cld- } 2 \uparrow\end{array}$ & & \\
\hline & T404A & Occ exchange $\rightarrow$ & & \\
\hline \multirow{3}{*}{ VEGF S490 } & $\begin{array}{l}\text { overexpression/ } \\
\text { stimulation }\end{array}$ & $\begin{array}{c}\text { TER } \downarrow \\
\text { permeability } \uparrow\end{array}$ & \multirow{3}{*}{ BREC } & \multirow{3}{*}[100,101]{} \\
\hline & S490D-mutation & $\begin{array}{c}\text { interaction of Occ with ZO- } 1 \downarrow \\
\text { interaction of Occ with Itch } \uparrow \\
\text { Occ degradation } \uparrow\end{array}$ & & \\
\hline & S490A-mutation: & $\begin{array}{c}\text { junctional Occ } \uparrow \\
\text { interaction of Occ with Itch } \downarrow \\
\text { Occ degradation } \downarrow \\
\text { TER } \uparrow \\
\text { permeability } \downarrow\end{array}$ & & \\
\hline
\end{tabular}

triple-site mutated occludin-T400A/T404A/S408A or -T400E/T404E/S408E constructs, however, showed that the phosphomimetic construct increased TER and less efficiently bind to ZO-2 (Dörfel et al., unpublished results). Nevertheless, it can be concluded that the amino acid sequence motif $400-$ 408 represents a hot spot for Ser/Thr kinases including PKCs and CK2, which is critically involved in the regulation of TJ structure and function (see Figure 1). Future studies have to unravel whether phosphorylation of amino acids within this cluster may affect the formation of disulfide bonds and dimerization of occludin [93] especially under conditions of oxidative stress. 


\section{PI3K and Occludin Phosphorylation}

PI3K (phosphatidylinositol-3-kinase) signaling is involved in the regulation of multiple cellular processes including metabolism, proliferation, cell death, and migration. Deregulated activation of PI3K is frequently associated with cancer. PI3Ks are divided into three classes of proteins. Class I PI3Ks generate the second messenger phosphatidyl-3,4,5-trisphosphate $\left(\mathrm{PIP}_{3}\right)$ in phosphorylating the lipid phosphatidyl-4,5diphosphate. Class I PI3Ks are subdivided into classes IA and IB, activated by receptor tyrosine kinases (RTKs), or G protein-coupled receptors (GPCRs), respectively. Class IA PI3Ks are composed of regulatory subunits ( $\mathrm{p} 85 \alpha$, p85 $\beta$, and $\mathrm{p} 55 \gamma)$ and $\mathrm{p} 110(\alpha, \beta, \delta)$ catalytic subunits. Class IB kinases are characterized by p101 regulatory subunits and $\mathrm{p} 110 \gamma$ catalytic subunits. Both, class II and class III PI3Ks use phosphatidylinositol (PI) as a substrate and are involved in membrane trafficking and mTOR (mammalian target of rapamycin) signaling, respectively, (for review see [94]).

First evidence for a role of PI3K in occludin-dependent regulation of TJs was given by the observation that a peptide derived from the occludin coiled-coil domain pulls down the PI3K regulatory p85 subunit from T84 human adenocarcinoma cells [53]. Further evidence for involvement of PI3K was provided by treatment of Caco- 2 cells with the PI3K inhibitor LY294002 under oxidative stress conditions. Tyrosine phosphorylation of occludin and ZO-1, redistribution of both proteins to the intracellular compartment, decrease in TER, and increased permeability were significantly reduced in the presence of the inhibitor. Oxidative stress-induced translocation of p85 to junctions increased coprecipitation of the PI3K regulatory p 85 subunit and kinase activity with occludin. Direct binding to occludin was further confirmed using recombinant occludin C-terminus which associates with purified p85 subunit [59]. These observations suggested that PI3K activity is involved in dissociation of TJs. Contrary observations were reported for dexamethasone-treated Con8 rat mammary epithelial cells where PI3K activity contributes to TER increase [95]. Recently it has been reported that PI3K in addition to its lipd kinase activity also has protein kinase activity [96]. It is currently not clear, if amino acid residue/s in occludin can be directly phosphorylated by PI3K and whether this affects the regulation of TJs.

\section{VEGF-Induced Phosphorylation of Occludin}

The vascular endothelial growth factor (VEGF) family contains five structurally related mammalian ligands (VEGFA, VEGFB, VEGFC, VEGFD, and placenta growth factor PLGF) and three VEGF receptor tyrosine kinases (for review [97, 98]). They critically regulate vasculogenesis and angiogenesis and have early been identified to induce occludin phosphorylation thereby modulating barrier properties [99]. Although the downstream kinase is not jet identified, by analyzing crude membrane fractionations of bovine retinal endothelial cells (BRECs) $+/$ - VEGF stimulation and by combining mass spectrometry data analyses with bioinformatics, S490 in occludin was identified as the downstream phosphosite. This phosphorylation site was verified in vivo using a phospho-specific antibody. Mutation of serine 490 to aspartate resulted in diminished binding of the occludin C-terminal domain to ZO-1 [100]. Phosphorylation of S409 in occludin strengthens its interaction with the E3 ubiquitin ligase Itch and induces occludin ubiquitination [101]. As shown earlier, Itch interacts with the N-terminal domain of occludin, ubiquitinates occludin and targets it to proteasomal degradation [102]. VEGF-induced ubiquitination strengthens the interaction of occludin, with modulators of intracellular trafficking including Epsin-1, epidermal growth factor receptor pathway substrate 15 (Eps15), and hepatocyte growth factor-regulated tyrosine kinase substrate (Hrs) and induces its degradation. Administration of VEGF to BRECs induces the fragmentation of TJs as measured by a decrease in TER and increased permeability of the tracer $70-\mathrm{kDa}$-rhodamine $B$ isothiocyanate dextran. Occludin trafficking from the cell border to early and late endosomes was enhanced, whereas a S490A mutation suppressed these VEGF effects. These observations for the first time linked occludin phosphorylation with degradation pathways.

\section{Phosphatases Counteracting Occludin Phosphorylation}

To achieve the highly coordinated regulation of cellular signaling pathways, the action of most kinases has to be reverted by specific phosphatase reactions. In the context of occludin phosphorylation, PP2A, PP1 and DEP-1 were identified as phosphatases that are able to counteract serine/threonine and tyrosine kinase activities, respectively. Nevertheless, much less is known about occludin phosphatases and it is assumed that further phosphatases able to modulate occludin and $\mathrm{TJ}$ function will be identified.

Protein phosphatase 1 (PP1) and PP2A represent the major protein Ser/Thr phosphatases in eukaryotic cells. They are ubiquitously expressed in all eukaryotic organisms with multiple functions (for review see [103]). The functional PP1 enzyme consists of a highly conserved catalytic subunit associated with one out of many regulatory subunits. More than 100 putative regulatory subunits have been identified, which define localization and/or substrate specificity of the enzyme. PP2A is composed of a heterodimeric core enzyme, consisting of a scaffold subunit (A, PR65) and catalytic subunit (C), which interacts with variable regulatory subunits (B) to form the active PP2A holoenzyme. The B subunits determine targeting of PP2A to specific intracellular domains and define recruitment to distinct signaling complexes. The expression levels of these regulatory subunits are variable between different tissues and cell types. The receptor-type protein tyrosine phosphatase DEP-1 (density-enhanced protein tyrosine phosphatase-1), also known as CD148, PTP- $\eta$, high cell density-enhanced PTP (HPTP- $\eta$ ), is a member of the type III family of protein tyrosine phosphatases (PTPs) and is widely expressed in many cell types including epithelial and endothelial cells. A tumor suppressor function was associated with DEP-1 in genetic studies, which is supported by known substrates including c-Met (HGFR), p120 ctn, c-Src, and PI3K (for review see [104]). 
Inhibition of PTPs in human umbilical vein endothelial cells (HUVECs) by phenylarsine oxide or pervanadate induces metalloproteinase-mediated progressive disappearance of occludin from the cell-cell contacts and elevates permeability of FITC-dextrans (4.4 kDa and $38.26 \mathrm{kDa})$ [105]. Further studies by Nunbhakdi-Craig et al. [106] revealed that the PP2A holoenzyme containing the $\mathrm{B} \alpha$ subunit dissociates from junctional contacts in response to lowering of $\mathrm{Ca}^{2+}$ in the medium and redistributes to junctional complexes after readdition of $\mathrm{Ca}^{2+}$. A recent report has suggested that hypoglycosylated E-cadherin enhanced recruitment of PP2A to adherens junctions. This resulted in diminished binding of PP2A to ZO-1 and claudin-1, and thus more ZO-1 was found associated with occludin and claudin-1 correlating with increased TER [107]. In coimmunoprecipitation experiments with an anti-B $\alpha$ antibody, occludin, claudin-1, and ZO-1 formed a complex with PP2A. This observation was confirmed in vice versa experiments with an anti-occludin antibody precipitating $\mathrm{B} \alpha$ from rat colon and kidney homogenates. The inhibition of PP2A activity with ocadaic acid (OA) enhanced occludin phosphorylation, accelerated TJ assembly, and increased TER. Moreover, this study shows that occludin, which was prephosphorylated by $\mathrm{aPKC} \zeta$, is dephosphorylated by PP2A. Interestingly, PP2A associates with $\mathrm{PKC} \zeta$ in coimmunoprecipitation experiments and appears to be involved in the regulation of $\mathrm{PKC} \zeta$. In MDCK cells overexpressing the catalytic subunit of $\mathrm{PP} 2 \mathrm{~A}$, recruitment of PKC $\zeta$ to junctional complexes was impaired during TJ biogenesis [106]. In pulmonary adenocarinoma Calu-3 cells, Vermeer et al. [108] showed a similar complex formation between PP2A and occludin, claudin- 1 and $\mathrm{aPKC} \lambda$ at the cell junctions and dissociation of PP2A from occludin and claudins when TJs are disintegrated. Disruption of TJs is a prerequisite for apically secreted EGF ligands to activate their basolateral receptors [109]. Concomitant with an EGF-induced tyrosine phosphorylation of the PP2A catalytic subunit, PP2A is inactivated allowing phosphorylation of aPKC and its translocation to tight junctional complexes thus promoting assembly [106, 108]. Under inflammatory conditions, which were simulated by $\mathrm{TNF} \alpha / \mathrm{IFN} \gamma$ treatment, junctional integrity was compromised leading to a drop in TER which was reverted in the presence of ocadaic acid [108]. Thus, accessibility of Erb receptors for their ligands, leading to PP2A inactivation, allows rapid restoration of barrier integrity essential to protect the epithelium from environmental insults.

Treatment of Caco-2 cells with EGTA to induce opening of TJs increases the direct association of the occludin C-terminal domain with the catalytic subunit of PP2A and of PP1 and vice versa, whereas readdition of $\mathrm{Ca}^{2+}$ gradually reduced this interaction. Knockdown of PP2A or PP1 accelerates TJ assembly, recovery of TER, and barrier function. Interestingly, in in vitro phosphatase assays, PP2A dephosphorylates the occludin C-terminus on phospho-threonine residues, whereas $\mathrm{PP} 1 \alpha$ dephosphorylates it on phosphoserine residues [110]. However, the in vivo roles of occludin serine phosphorylation and PP1 currently are not clear. It was speculated that serine phosphorylation of occludin may stabilize TJs once they are assembled, or that PP1 associates with occludin to target other components of the TJ complex [110]. Consistent with the previous findings, $\mathrm{H}_{2} \mathrm{O}_{2}$-induced disassembly of TJs was associated with PP2A-mediated dephosphorylation of occludin. Interestingly, tyrosine phosphorylation of GST-occludin C-terminus enhanced PP2A binding.

The important role of serine/threonine phosphatases for the TJ barrier properties was emphasized by the finding that enteropathogenic E. coli-induced disruption of TJs was blocked by calyculin A [111].

Using a catalytically dead substrate-trapping mutant, the receptor tyrosine phosphatase DEP-1 has been shown to interact with occludin in a tyrosine phosphorylation-dependent manner in MCF10A and MDCK II cells, whereas PTPPEST, Shp2, or PTP $\mu$ did not bind. Overexpression of DEP-1 enhances barrier function during TJ reassembly whereas a knockdown of DEP-1 increased epithelial permeability [112].

\section{Conclusions}

Multiple kinases targeting occludin and thereby modulating TJ assembly, structure, and function have been characterized and specific serine, threonine, and tyrosine residues targeted by these kinases have been identified (for summary see Table 1). Currently, it is well accepted that tyrosine phosphorylation destabilizes TJs whereas especially threonine phosphorylation by atypical PKCs promotes TJ assembly. In addition to those kinases discussed here in more detail, further kinases have been suggested to be involved in the modulation of TJ function including p34cdc2/cyclinB [90], ATM/ ATR [113], AMPK, and GSK3 $\beta$ [114]. However, direct binding and phosphorylation sites have to be defined for most of them. Dynamic phosphorylation of occludin appears to play an important role in the assembly/disassembly of TJs. Thus, phosphorylation and dephosphorylation of occludin has to be exactly balanced. Whether and how sequential actions of kinases are involved in these processes is currently not clear. Depending on the stimulus, the sequence of phosphorylations or the targeted amino acid residues may change. It is noteworthy that within the occludin C-terminal domain a hotspot for phosphorylation events exists between Y398S408 that is used by PKC $\eta$ and $\zeta$, Src kinase and CK2 (see Figure 1). It is likely that the cooperation of multiple kinases within this stretch of 10 amino acids modulates the charge distribution in occludin thereby regulating occludin function.

The generation of further phospho-site-specific antibodies will be a helpful tool for future investigations in this direction. Recent studies clearly have indicated that the mobility of TJ components and protein-protein interactions within the TJ complex are differentially regulated $[18,92]$. Whether the mobility of these components and in consequence their interaction is specifically regulated by the different kinases has to be investigated. Currently, most studies focused on the phosphorylation of the occludin C-terminal domain. However, little is known about the $\mathrm{N}$-terminus in this respect. Experiments showing that the occludin N-terminus is phosphorylated in vitro, [87] suggest that this may also occur in 
vivo, for example, in the regulation of Itch-dependent occludin ubiquitination and degradation. Probably, also new context-specific phosphatases counter-acting kinase activities will be identified. If these kinases and phosphatases are useful targets for therapeutic treatment of diseases such as inflammatory gastrointestinal or pulmonary diseases, or whether they can be applied to target the blood-brain barrier, are open questions for intriguing investigations in the future.

\section{Acknowledgments}

The authors gratefully acknowledge support by the DFG research group FOR721 (HU881/4-1 and -2). They apologize to those whose work they did not specifically cite in this review. They thank Sonnhild Mittag for critically reading the manuscript.

\section{References}

[1] L. A. Staehelin, "Further observations on the fine structure of freeze cleaved tight junctions," Journal of Cell Science, vol. 13, no. 3, pp. 763-786, 1973.

[2] L. Shen, C. R. Weber, D. R. Raleigh, D. Yu, and J. R. Turner, "Tight junction pore and leak pathways: a dynamic duo," Annual Review of Physiology, vol. 73, pp. 283-309, 2011.

[3] S. M. Krug, M. Fromm, and D. Günzel, "Two-path impedance spectroscopy for measuring paracellular and transcellular epithelial resistance," Biophysical Journal, vol. 97, no. 8, pp. 2202-2211, 2009.

[4] S. Tsukita, M. Furuse, and M. Itoh, "Multifunctional strands in tight junctions," Nature Reviews Molecular Cell Biology, vol. 2, no. 4, pp. 285-293, 2001.

[5] L. González-Mariscal, A. Betanzos, P. Nava, and B. E. Jaramillo, "Tight junction proteins," Progress in Biophysics and Molecular Biology, vol. 81, no. 1, pp. 1-44, 2003.

[6] K. Umeda, T. Matsui, M. Nakayama et al., "Establishment and characterization of cultured epithelial cells lacking expression of ZO-1," Journal of Biological Chemistry, vol. 279, no. 43, pp. 44785-44794, 2004.

[7] J. Xu, P. J. Kausalya, D. C. Y. Phua, S. M. Ali, Z. Hossain, and W. Hunziker, "Early embryonic lethality of mice lacking ZO2 , but not ZO-3, reveals critical and nonredundant roles for individual zonula occludens proteins in mammalian development," Molecular and Cellular Biology, vol. 28, no. 5, pp. 1669-1678, 2008.

[8] K. Umeda, J. Ikenouchi, S. Katahira-Tayama et al., "ZO-1 and ZO-2 independently determine where claudins are polymerized in tight-junction strand formation," Cell, vol. 126, no. 4, pp. 741-754, 2006.

[9] L. Guillemot, S. Paschoud, P. Pulimeno, A. Foglia, and S. Citi, "The cytoplasmic plaque of tight junctions: a scaffolding and signalling center," Biochimica et Biophysica Acta, vol. 1778, no. 3, pp. 601-613, 2008.

[10] M. Furuse, T. Hirase, M. Itoh et al., "Occludin: a novel integral membrane protein localizing at tight junctions," Journal of Cell Biology, vol. 123, no. 6, pp. 1777-1788, 1993.

[11] J. M. Anderson and C. M. van Itallie, "Physiology and function of the tight junction," Cold Spring Harbor Perspectives in Biology, vol. 1, no. 2, p. a002584, 2009.

[12] M. Furuse and S. Tsukita, "Claudins in occluding junctions of humans and flies," Trends in Cell Biology, vol. 16, no. 4, pp. 181-188, 2006.
[13] G. Krause, L. Winkler, S. L. Mueller, R. F. Haseloff, J. Piontek, and I. E. Blasig, "Structure and function of claudins," Biochimica et Biophysica Acta, vol. 1778, no. 3, pp. 631-645, 2008.

[14] C. M. van Itallie and J. M. Anderson, "Claudins and epithelial paracellular transport," Annual Review of Physiology, vol. 68, pp. 403-429, 2006.

[15] L. Sánchez-Pulido, F. Martín-Belmonte, A. Valencia, and M. A. Alonso, "MARVEL: a conserved domain involved in membrane apposition events," Trends in Biochemical Sciences, vol. 27, no. 12, pp. 599-601, 2002.

[16] S. M. Krug, S. Amasheh, J. F. Richter et al., "Tricellulin forms a barrier to macromolecules in tricellular tight junctions without affecting ion permeability," Molecular Biology of the Cell, vol. 20, no. 16, pp. 3713-3724, 2009.

[17] J. Ikenouchi, M. Furuse, K. Furuse, H. Sasaki, S. Tsukita, and S. Tsukita, "Tricellulin constitutes a novel barrier at tricellular contacts of epithelial cells," Journal of Cell Biology, vol. 171, no. 6, pp. 939-945, 2005.

[18] D. R. Raleigh, A. M. Marchiando, Y. Zhang et al., "Tight junction-associated MARVEL proteins marvelD3, tricellulin, and occludin have distinct but overlapping functions," Molecular Biology of the Cell, vol. 21, no. 7, pp. 1200-1213, 2010.

[19] E. Steed, N. T. L. Rodrigues, M. S. Balda, and K. Matter, "Identification of MarvelD3 as a tight junction-associated transmembrane protein of the occludin family," BMC Cell Biology, vol. 10, article 95, 2009.

[20] J. K. Westphal, M. J. Dörfel, S. M. Krug et al., “Tricellulin forms homomeric and heteromeric tight junctional complexes," Cellular and Molecular Life Sciences, vol. 67, no. 12, pp. 2057-2068, 2010.

[21] G. Bazzoni, "The JAM family of junctional adhesion molecules," Current Opinion in Cell Biology, vol. 15, no. 5, pp. 525530, 2003.

[22] G. Bazzoni, "Pathobiology of junctional adhesion molecules," Antioxidants and Redox Signaling, vol. 15, no. 5, pp. 1221-1234, 2011.

[23] C. J. Cohen, J. T. Shieh, R. J. Pickles, T. Okegawa, J. T. Hsieh, and J. M. Bergelson, "The coxsackievirus and adenovirus receptor is a transmembrane component of the tight junction," Proceedings of the National Academy of Sciences of the United States of America, vol. 98, no. 26, pp. 15191-15196, 2001.

[24] I. Nasdala, K. Wolburg-Buchholz, H. Wolburg et al., "A transmembrane tight junction protein selectively expressed on endothelial cells and platelets," Journal of Biological Chemistry, vol. 277, no. 18, pp. 16294-16303, 2002.

[25] M. Saitou, Y. Ando-Akatsuka, M. Itoh et al., "Mammalian occludin in epithelial cells: its expression and subcellular distribution," European Journal of Cell Biology, vol. 73, no. 3, pp. 222-231, 1997.

[26] J. Mankertz, J. S. Waller, B. Hillenbrand et al., "Gene expression of the tight junction protein occludin includes differential splicing and alternative promoter usage," Biochemical and Biophysical Research Communications, vol. 298, no. 5, pp. 657-666, 2002.

[27] M. Furuse, K. Fujimoto, N. Sato, T. Hirase, S. Tsukita, and S. Tsukita, "Overexpression of occludin, a tight junction-associated integral membrane protein, induces the formation of intracellular multilamellar bodies bearing tight junction-like structures," Journal of Cell Science, vol. 109, no. 2, pp. 429435, 1996.

[28] M. S. Balda, J. A. Whitney, C. Flores, S. González, M. Cereijido, and K. Matter, "Functional dissociation of paracellular permeability and transepithelial electrical resistance and 
disruption of the apical-basolateral intramembrane diffusion barrier by expression of a mutant tight junction membrane protein," Journal of Cell Biology, vol. 134, no. 4, pp. 10311049, 1996.

[29] K. M. McCarthy, I. B. Skare, M. C. Stankewich et al., "Occludin is a functional component of the tight junction," Journal of Cell Science, vol. 109, no. 9, pp. 2287-2298, 1996.

[30] I. E. Blasig, C. Bellmann, J. Cording et al., "Occludin protein family: oxidative stress and reducing conditions," Antioxidants and Redox Signaling, vol. 15, no. 5, pp. 1195-1219, 2011.

[31] M. S. Balda, C. Flores-Maldonado, M. Cereijido, and K. Matter, "Multiple domains of occludin are involved in the regulation of paracellular permeability," Journal of Cellular Biochemistry, vol. 78, no. 1, pp. 85-96, 2000.

[32] M. Saitou, M. Furuse, H. Sasaki et al., "Complex phenotype of mice lacking occludin, a component of tight junction strands," Molecular Biology of the Cell, vol. 11, no. 12, pp. 4131-4142, 2000.

[33] J. D. Schulzke, A. H. Gitter, J. Mankertz et al., "Epithelial transport and barrier function in occludin-deficient mice," Biochimica et Biophysica Acta, vol. 1669, no. 1, pp. 34-42, 2005.

[34] M. Furuse, K. Fujita, T. Hiiragi, K. Fujimoto, and S. Tsukita, "Claudin-1 and -2: novel integral membrane proteins localizing at tight junctions with no sequence similarity to occludin," Journal of Cell Biology, vol. 141, no. 7, pp. 1539-1550, 1998.

[35] M. Furuse, H. Sasaki, K. Fujimoto, and S. Tsukita, "A single gene product, claudin-1 or -2 , reconstitutes tight junction strands and recruits occludin in fibroblasts," Journal of Cell Biology, vol. 143, no. 2, pp. 391-401, 1998.

[36] A. S. L. Yu, K. M. McCarthy, S. A. Francis et al., "Knockdown of occludin expression leads to diverse phenotypic alterations in epithelial cells," American Journal of Physiology, vol. 288, no. 6, pp. C1231-C1241, 2005.

[37] J. Ikenouchi, H. Sasaki, S. Tsukita, M. Furuse, and S. Tsukita, "Loss of occludin affects tricellular localization of tricellulin," Molecular Biology of the Cell, vol. 19, no. 11, pp. 4687-4693, 2008.

[38] C. M. van Itallie, A. S. Fanning, J. Holmes, and J. M. Anderson, "Occludin is required for cytokine-induced regulation of tight junction barriers," Journal of Cell Science, vol. 123, no. 16, pp. 2844-2852, 2010.

[39] S. Masuda, Y. Oda, H. Sasaki et al., "LSR defines cell corners for tricellular tight junction formation in epithelial cells," Journal of Cell Science, vol. 124, no. 4, pp. 548-555, 2011.

[40] C. T. Capaldo and A. Nusrat, "Cytokine regulation of tight junctions," Biochimica et Biophysica Acta, vol. 1788, no. 4, pp. 864-871, 2009.

[41] L. González-Mariscal, S. Hernández, and J. Vega, "Inventions designed to enhance drug delivery across epithelial and endothelial cells through tha paracellular pathway," Recent Patents on Drug Delivery and Formulation, vol. 2, no. 2, pp. 145-176, 2008.

[42] K. Matter, S. Aijaz, A. Tsapara, and M. S. Balda, "Mammalian tight junctions in the regulation of epithelial differentiation and proliferation," Current Opinion in Cell Biology, vol. 17, no. 5, pp. 453-458, 2005.

[43] K. Matter and M. S. Balda, "Signalling to and from tight junctions," Nature Reviews Molecular Cell Biology, vol. 4, no. 3, pp. 225-236, 2003.
[44] A. M. Marchiando, L. Shen, W. V. Graham et al., "Caveolin-1dependent occludin endocytosis is required for TNF-induced tight junction regulation in vivo," Journal of Cell Biology, vol. 189, no. 1, pp. 111-126, 2010.

[45] S. Samarin and A. Nusrat, "Regulation of epithelial apical junctional complex by Rho family GTPases," Frontiers in Bioscience, vol. 14, pp. 1129-1142, 2009.

[46] S. J. Terry, C. Zihni, A. Elbediwy et al., "Spatially restricted activation of RhoA signalling at epithelial junctions by p114RhoGEF drives junction formation and morphogenesis," $\mathrm{Na}$ ture Cell Biology, vol. 13, no. 2, pp. 159-166, 2011.

[47] S. Aijaz, F. D’Atri, S. Citi, M. S. Balda, and K. Matter, "Binding of GEF-H1 to the tight junction-associated adaptor cingulin results in inhibition of Rho signaling and G1/S phase transition," Developmental Cell, vol. 8, no. 5, pp. 777-786, 2005.

[48] M. S. Balda and K. Matter, "Epithelial cell adhesion and the regulation of gene expression," Trends in Cell Biology, vol. 13, no. 6, pp. 310-318, 2003.

[49] K. Matter and M. S. Balda, "Epithelial tight junctions, gene expression and nucleo-junctional interplay," Journal of Cell Science, vol. 120, no. 9, pp. 1505-1511, 2007.

[50] L. C. Kim, L. Song, and E. B. Haura, "Src kinases as therapeutic targets for cancer," Nature Reviews Clinical Oncology, vol. 6, no. 10, pp. 587-595, 2009.

[51] T. N. Meyer, C. Schwesinger, J. Ye, B. M. Denker, and S. K. Nigam, "Reassembly of the tight junction after oxidative stress depends on tyrosine kinase activity," Journal of Biological Chemistry, vol. 276, no. 25, pp. 22048-22055, 2001.

[52] Y. H. Chen, Q. Lu, E. E. Schneeberger, and D. A. Goodenough, "Restoration of tight junction structure and barrier function by down-regulation of the mitogen-activated protein kinase pathway in Ras-transformed Madin-Darby canine kidney cells," Molecular Biology of the Cell, vol. 11, no. 3, pp. 849-862, 2000.

[53] A. Nusrat, J. A. Chen, C. S. Foley et al., "The coiled-coil domain of occludin can act to organize structural and functional elements of the epithelial tight junction," Journal of Biological Chemistry, vol. 275, no. 38, pp. 29816-29822, 2000.

[54] X. Xiao, D. D. Mruk, W. M. Lee, and C. Y. Cheng, "c-Yes regulates cell adhesion at the blood-testis barrier and the apical ectoplasmic specialization in the seminiferous epithelium of rat testes," International Journal of Biochemistry and Cell Biology, vol. 43, no. 4, pp. 651-665, 2011.

[55] S. Basuroy, P. Sheth, D. Kuppuswamy, S. Balasubramanian, R. M. Ray, and R. K. Rao, "Expression of kinase-inactive c-Src delays oxidative stress-induced disassembly and accelerates calcium-mediated reassembly of tight junctions in the Caco2 cell monolayer," Journal of Biological Chemistry, vol. 278, no. 14, pp. 11916-11924, 2003.

[56] G. Kale, A. P. Naren, P. Sheth, and R. K. Rao, "Tyrosine phosphorylation of occludin attenuates its interactions with ZO1, ZO-2, and ZO-3," Biochemical and Biophysical Research Communications, vol. 302, no. 2, pp. 324-329, 2003.

[57] B. C. Elias, T. Suzuki, A. Seth et al., "Phosphorylation of Tyr398 and Tyr-402 in occludin prevents Its interaction with ZO-1 and destabilizes Its assembly at the tight junctions," Journal of Biological Chemistry, vol. 284, no. 3, pp. 15591569, 2009.

[58] D. Du, F. Xu, L. Yu et al., "The tight junction protein, occludin, regulates the directional migration of epithelial cells," Developmental Cell, vol. 18, no. 1, pp. 52-63, 2010. 
[59] P. Sheth, S. Basuroy, C. Li, A. P. Naren, and R. K. Rao, "Role of phosphatidylinositol 3-kinase in oxidative stress-induced disruption of tight junctions," The Journal of Biological Chemistry, vol. 278, no. 49, pp. 49239-49245, 2003.

[60] M. D. Schaller, "Cellular functions of FAK kinases: insight into molecular mechanisms and novel functions," Journal of Cell Science, vol. 123, no. 7, pp. 1007-1013, 2010.

[61] N. Zebda, O. Dubrovskyi, and K. G. Birukov, "Focal adhesion kinase regulation of mechanotransduction and its impact on endothelial cell functions," Microvascular Research, vol. 83, no. 1, pp. 71-81, 2012.

[62] S. Basuroy, P. Sheth, C. M. Mansbach, and R. K. Rao, "Acetaldehyde disrupts tight junctions and adherens junctions in human colonic mucosa: protection by EGF and L-glutamine," American Journal of Physiology, vol. 289, no. 2, pp. G367-G375, 2005.

[63] E. R. Siu, E. W. Wong, D. D. Mruk, C. S. Porto, and C. Y. Cheng, "Focal adhesion kinase is a blood-testis barrier regulator," Proceedings of the National Academy of Sciences of the United States of America, vol. 106, no. 23, pp. 9298-9303, 2009.

[64] M. Amano, M. Nakayama, and K. Kaibuchi, "Rho-kinase/ ROCK: a key regulator of the cytoskeleton and cell polarity," Cytoskeleton, vol. 67, no. 9, pp. 545-554, 2010.

[65] S. Gopalakrishnan, N. Raman, S. J. Atkinson, and J. A. Marrs, "Rho GTPase signaling regulates tight junction assembly and protects tight junctions during ATP depletion," American Journal of Physiology, vol. 275, no. 3, pp. C798-C809, 1998.

[66] A. Nusrat, M. Giry, J. R. Turner et al., "Rho protein regulates tight junctions and perijunctional actin organization in polarized epithelia," Proceedings of the National Academy of Sciences of the United States of America, vol. 92, no. 23, pp. 10629-10633, 1995.

[67] T. Hirase, S. Kawashima, E. Y. Wong et al., "Regulation of tight junction permeability and occludin phosphorylation by RhoA-p160ROCK-dependent and -independent mechanisms," Journal of Biological Chemistry, vol. 276, no. 13, pp. 10423-10431, 2001.

[68] Y. Persidsky, D. Heilman, J. Haorah et al., "Rho-mediated regulation of tight junctions during monocyte migration across the blood-brain barrier in HIV-1 encephalitis (HIVE)," Blood, vol. 107, no. 12, pp. 4770-4780, 2006.

[69] M. Yamamoto, S. H. Ramirez, S. Sato et al., "Phosphorylation of claudin- 5 and occludin by Rho kinase in brain endothelial cells," American Journal of Pathology, vol. 172, no. 2, pp. 521533, 2008.

[70] E. K. Kim and E. J. Choi, "Pathological roles of MAPK signaling pathways in human diseases," Biochimica et Biophysica Acta, vol. 1802, no. 4, pp. 396-405, 2010.

[71] R. G. Contreras, L. Shoshani, C. Flores-Maldonado, A. Lázaro, and M. Cereijido, "Relationship between $\mathrm{Na}^{+}, \mathrm{K}^{+}$ATPase and cell attachment," Journal of Cell Science, vol. 112, no. 23, pp. 4223-4232, 1999.

[72] Y. Wang, J. Zhang, X. J. Yi, and F. S. Yu, "Activation of ERK1/2 MAP kinase pathway induces tight junction disruption in human corneal epithelial cells," Experimental Eye Research, vol. 78, no. 1, pp. 125-136, 2004.

[73] D. Li and R. J. Mrsny, "Oncogenic Raf-1 disrupts epithelial tight junctions via downregulation of occludin," Journal of Cell Biology, vol. 148, no. 4, pp. 791-800, 2000.

[74] S. Basuroy, A. Seth, B. Elias, A. P. Naren, and R. Rao, "MAPK interacts with occludin and mediates EGF-induced prevention of tight junction disruption by hydrogen peroxide," Biochemical Journal, vol. 393, no. 1, pp. 69-77, 2006.
[75] S. Aggarwal, T. Suzuki, W. L. Taylor, A. Bhargava, and R. K. Rao, "Contrasting effects of ERK on tight junction integrity in differentiated and under-differentiated Caco-2 cell monolayers," Biochemical Journal, vol. 433, no. 1, pp. 51-63, 2011.

[76] V. Poulaki, E. Iliaki, N. Mitsiades et al., "Inhibition of Hsp90 attenuates inflammation in endotoxin-induced uveitis," FASEB Journal, vol. 21, no. 9, pp. 2113-2123, 2007.

[77] G. Samak, S. Aggarwal, and R. K. Rao, "ERK is involved in EGF-mediated protection of tight junctions, but not adherens junctions, in acetaldehyde-treated Caco-2 cell monolayers," American Journal of Physiology, vol. 301, no. 1, pp. G50G59, 2011.

[78] G. Samak, T. Suzuki, A. Bhargava, and R. K. Rao, "c-Jun NH2-terminal kinase-2 mediates osmotic stress-induced tight junction disruption in the intestinal epithelium," American Journal of Physiology, vol. 299, no. 3, pp. G572-G584, 2010.

[79] S. F. Steinberg, "Structural basis of protein kinase C isoform function," Physiological Reviews, vol. 88, no. 4, pp. 13411378, 2008.

[80] R. O. Stuart and S. K. Nigam, "Regulated assembly of tight junctions by protein kinase C," Proceedings of the National Academy of Sciences of the United States of America, vol. 92, no. 13, pp. 6072-6076, 1995.

[81] A. Y. Andreeva, E. Krause, E. C. Müller, I. E. Blasig, and D. I. Utepbergenov, "Protein kinase $\mathrm{C}$ regulates the phosphorylation and cellular localization of occludin," Journal of Biological Chemistry, vol. 276, no. 42, pp. 38480-38486, 2001.

[82] A. Y. Andreeva, J. Piontek, I. E. Blasig, and D. I. Utepbergenov, "Assembly of tight junction is regulated by the antagonism of conventional and novel protein kinase C isoforms," International Journal of Biochemistry and Cell Biology, vol. 38, no. 2, pp. 222-233, 2006.

[83] T. Suzuki, B. C. Elias, A. Seth et al., "PKCeta regulates occludin phosphorylation and epithelial tight junction integrity," Proceedings of the National Academy of Sciences of the United States of America, vol. 106, no. 1, pp. 61-66, 2009.

[84] S. Jain, T. Suzuki, A. Seth, G. Samak, and R. Rao, "Protein kinase Czeta phosphorylates occludin and promotes assembly of epithelial tight junctions," Biochemical Journal, vol. 437, no. 2, pp. 289-299, 2011.

[85] J. K. Cheong and D. M. Virshup, "Casein kinase 1: complexity in the family," International Journal of Biochemistry and Cell Biology, vol. 43, pp. 465-469, 2011.

[86] J. A. G. McKenzie, K. Riento, and A. J. Ridley, "Casein kinase I $\varepsilon$ associates with and phosphorylates the tight junction protein occludin," FEBS Letters, vol. 580, no. 9, pp. 2388-2394, 2006.

[87] M. J. Dörfel, J. K. Westphal, and O. Huber, "Differential phosphorylation of occludin and tricellulin by CK2 and CK1," Annals of the New York Academy of Sciences, vol. 1165, pp. 69-73, 2009.

[88] O. Filhol and C. Cochet, "Protein kinase CK2 in health and disease: cellular functions of protein kinase CK2: a dynamic affair," Cellular and Molecular Life Sciences, vol. 66, no. 11-12, pp. 1830-1839, 2009.

[89] N. A. St-Denis and D. W. Litchfield, "Protein kinase CK2 in health and disease: from birth to death: the role of protein kinase CK2 in the regulation of cell proliferation and survival," Cellular and Molecular Life Sciences, vol. 66, no. 11-12, pp. 1817-1829, 2009. 
[90] M. Cordenonsi, F. Turco, F. D’Atri et al., "Xenopus laevis occludin: identification of in vitro phosphorylation sites by protein kinase CK2 and association with cingulin," European Journal of Biochemistry, vol. 264, no. 2, pp. 374-384, 1999.

[91] C. Smales, M. Ellis, R. Baumber, N. Hussain, H. Desmond, and J. M. Staddon, "Occludin phosphorylation: identification of an occludin kinase in brain and cell extracts as CK2," FEBS Letters, vol. 545, no. 2-3, pp. 161-166, 2003.

[92] D. R. Raleigh, D. M. Boe, D. Yu et al., "Occludin S408 phosphorylation regulates tight junction protein interactions and barrier function," Journal of Cell Biology, vol. 193, no. 3, pp. 565-582, 2011.

[93] J. K. Walter, V. Castro, M. Voss et al., "Redox-sensitivity of the dimerization of occludin," Cellular and Molecular Life Sciences, vol. 66, no. 22, pp. 3655-3662, 2009.

[94] N. Chalhoub and S. J. Baker, "PTEN and the PI3-kinase pathway in cancer," Annual Review of Pathology, vol. 4, pp. 127$150,2009$.

[95] P. L. Woo, D. Ching, Y. Guan, and G. L. Firestone, "Requirement for Ras and phosphatidylinositol 3-kinase signaling uncouples the glucocorticoid-induced junctional organization and transepithelial electrical resistance in mammary tumor cells," Journal of Biological Chemistry, vol. 274, no. 46, pp. 32818-32828, 1999.

[96] K. Lehmann, J. P. Müller, B. Schlott et al., "PI3K $\gamma$ controls oxidative bursts in neutrophils via interactions with $\mathrm{PKC} \alpha$ and p47phox," Biochemical Journal, vol. 419, no. 3, pp. 603$610,2009$.

[97] L. M. Ellis and D. J. Hicklin, "VEGF-targeted therapy: mechanisms of anti-tumour activity," Nature Reviews Cancer, vol. 8, no. 8 , pp. 579-591, 2008.

[98] S. Tugues, S. Koch, L. Gualandi, X. Li, and L. Claesson-Welsh, "Vascular endothelial growth factors and receptors: anti-angiogenic therapy in the treatment of cancer," Molecular Aspects of Medicine, vol. 32, no. 2, pp. 88-111, 2011.

[99] D. A. Antonetti, A. J. Barber, L. A. Hollinger, E. B. Wolpert, and T. W. Gardner, "Vascular endothelial growth factor induces rapid phosphorylation of tight junction proteins occludin and zonula occludens 1. A potential mechanism for vascular permeability in diabetic retinopathy and tumors," Journal of Biological Chemistry, vol. 274, no. 33, pp. 2346323467, 1999.

[100] J. M. Sundstrom, B. R. Tash, T. Murakami et al., "Identification and analysis of occludin phosphosites: a combined mass spectrometry and bioinformatics approach," Journal of Proteome Research, vol. 8, no. 2, pp. 808-817, 2009.

[101] T. Murakami, E. A. Felinski, and D. A. Antonetti, "Occludin phosphorylation and ubiquitination regulate tight junction trafficking and vascular endothelial growth factor-induced permeability," Journal of Biological Chemistry, vol. 284, no. 31, pp. 21036-21046, 2009.

[102] A. Traweger, D. Fang, Y. C. Liu et al., "The tight junctionspecific protein occludin is a functional target of the E3 ubiquitin-protein ligase Itch," Journal of Biological Chemistry, vol. 277, no. 12, pp. 10201-10208, 2002.

[103] Y. Shi, "Serine/threonine phosphatases: mechanism through structure," Cell, vol. 139, no. 3, pp. 468-484, 2009.

[104] M. L. Hermiston, J. Zikherman, and J. W. Zhu, "CD45, CD148, and Lyp/Pep: critical phosphatases regulating Src family kinase signaling networks in immune cells," Immunological Reviews, vol. 228, no. 1, pp. 288-311, 2009.

[105] M. Wachtel, K. Frei, E. Ehler, A. Fontana, K. Winterhalter, and S. M. Gloor, "Occludin proteolysis and increased permeability in endothelial cells through tyrosine phosphatase inhibition," Journal of Cell Science, vol. 112, no. 23, pp. 43474356, 1999.

[106] V. Nunbhakdi-Craig, T. Machleidt, E. Ogris, D. Bellotto, C. L. White III, and E. Sontag, "Protein phosphatase 2A associates with and regulates atypical $\mathrm{PKC}$ and the epithelial tight junction complex," Journal of Cell Biology, vol. 158, no. 5, pp. 967-978, 2002.

[107] M. Nita-Lazar, I. Rebustini, J. Walker, and M. A. Kukuruzinska, "Hypoglycosylated E-cadherin promotes the assembly of tight junctions through the recruitment of PP2A to adherens junctions," Experimental Cell Research, vol. 316, no. 11, pp. 1871-1884, 2010.

[108] P. D. Vermeer, L. Panko, M. J. Welsh, and J. Zabner, "ErbB1 functions as a sensor of airway epithelial integrity by regulation of protein phosphatase $2 \mathrm{~A}$ activity," Journal of Biological Chemistry, vol. 281, no. 3, pp. 1725-1730, 2006.

[109] P. D. Vermeer, L. A. Einwalter, T. O. Moninger et al., "Segregation of receptor and ligand regulates activation of epithelial growth factor receptor," Nature, vol. 422, no. 6929, pp. 322-326, 2003.

[110] A. Seth, P. Sheth, B. C. Elias, and R. Rao, "Protein phosphatases $2 \mathrm{~A}$ and 1 interact with occludin and negatively regulate the assembly of tight junctions in the CACO-2 cell monolayer," Journal of Biological Chemistry, vol. 282, no. 15, pp. 11487-11498, 2007.

[111] I. Simonovic, J. Rosenberg, A. Koutsouris, and G. Hecht, "Enteropathogenic Escherichia coli dephosphorylates and dissociates occludin from intestinal epithelial tight junctions," Cellular Microbiology, vol. 2, no. 4, pp. 305-315, 2000.

[112] J. L. Sallee and K. Burridge, "Density-enhanced phosphatase 1 regulates phosphorylation of tight junction proteins and enhances barrier function of epithelial cells," Journal of Biological Chemistry, vol. 284, no. 22, pp. 14997-15006, 2009.

[113] S. Matsuoka, B. A. Ballif, A. Smogorzewska et al., "ATM and ATR substrate analysis reveals extensive protein networks responsive to DNA damage," Science, vol. 316, no. 5828, pp. 1160-1166, 2007.

[114] L. Zhang, F. Jouret, J. Rinehart et al., "AMP-activated protein kinase (AMPK) activation and glycogen synthase kinase-3 $\beta$ (GSK-3 $\beta$ ) inhibition induce $\mathrm{Ca}^{2+}$-independent deposition of tight junction components at the plasma membrane," Journal of Biological Chemistry, vol. 286, no. 19, pp. 16879-16890, 2011. 

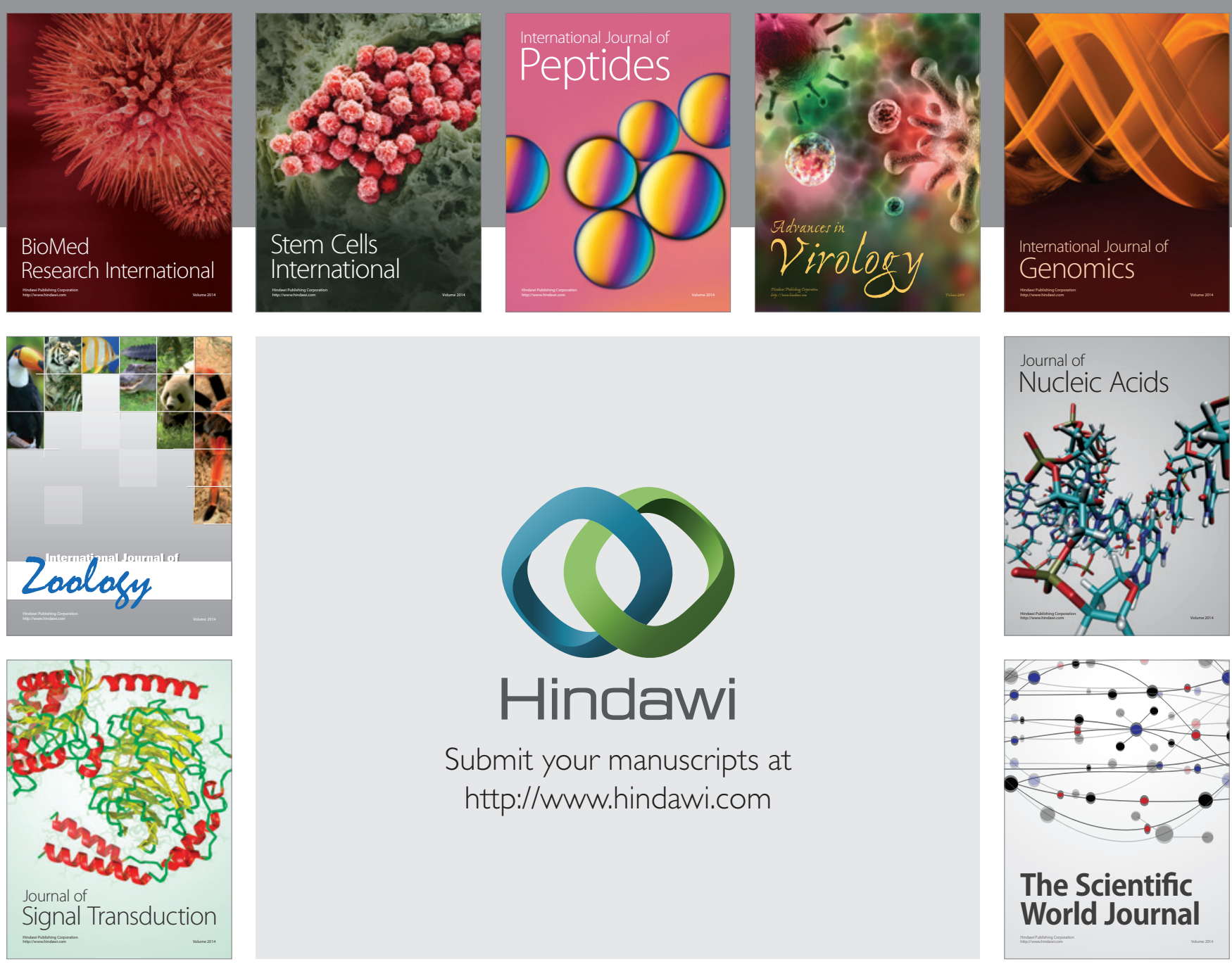

Submit your manuscripts at

http://www.hindawi.com
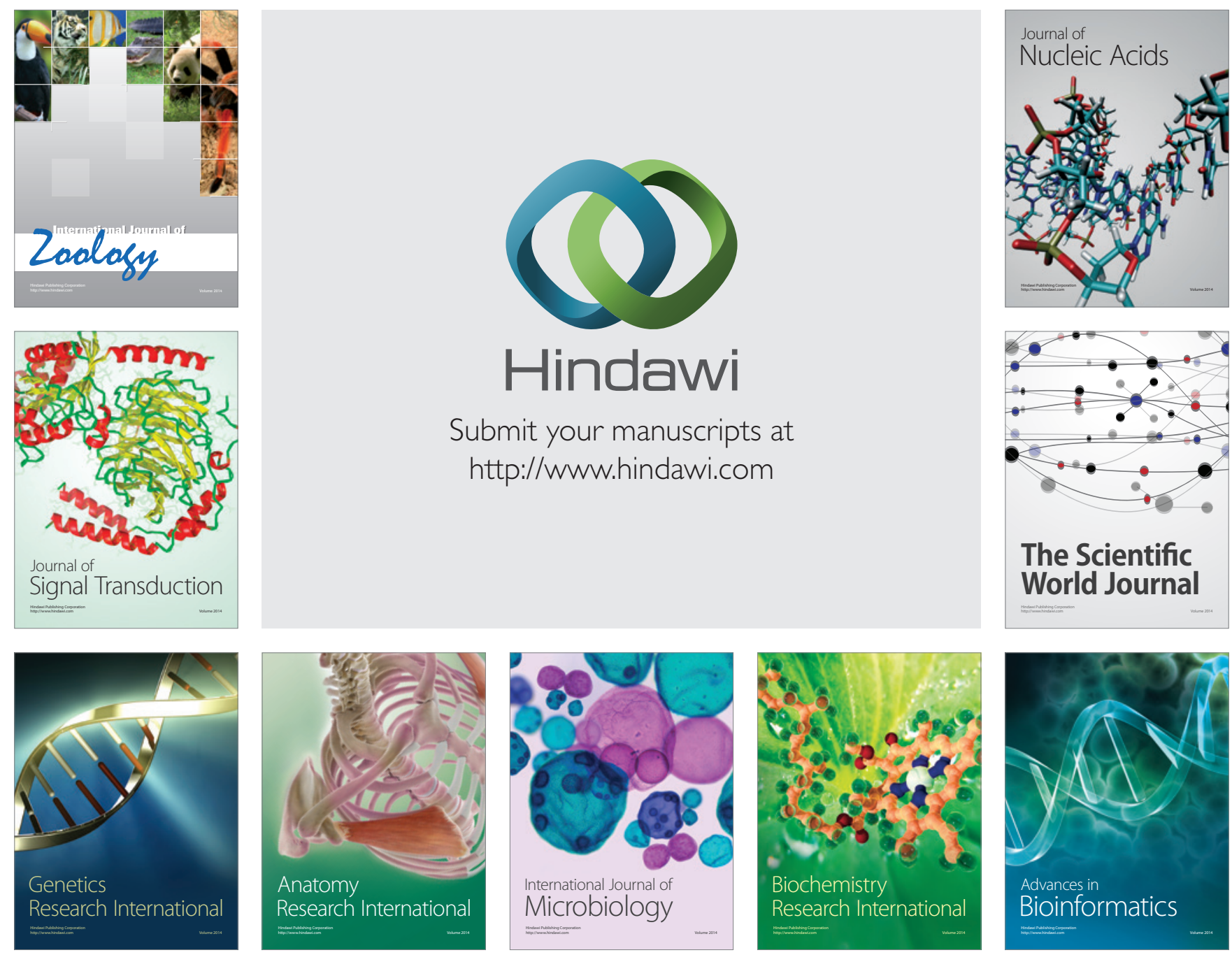

The Scientific World Journal
